\title{
PENGARUH HARGA, KUALITAS LAYANAN DAN TEKNOLOGI E-COMMERCE TERHADAP KEPUTUSAN UNTUK MENGGUNAKAN LAYANAN GO-JEK DI WILAYAH KECAMATAN CIBINONG
}

\author{
Yasnimar Ilyas \\ Dosen Program Studi Manajemen, STIE Dewantara \\ J1. Raya Pemda Bojong Depok Baru III, Karadenan, Cibinong, Bogor, Jawa Barat 16913,Indonesia \\ Email: yasnimar.ilyas@dewantara.ac.id
}

\begin{abstract}
In this era, some people use E-commerce for online transportation. Go-Jek is one of the alternatif online transportation that used by people. The aim of the research is to know the effect of factor cost, quality of services, and E-Commerce technologi to decision for using GoJek service in Kecamatan Cibinong. The type of research is used correlational research. The data analysis is used linear regression of multiple with helping SPSS program version 17.0. Result of the research shows the test linear regression of multiple obtained the regression equation is: $Y=3.340+0,631 X 1+0,180 X 2+0,678 X 3$. The meaning is every it increases the values of free variable (cost, quality of services, and E-Commerce) so it will increase the value of customers decision using Go-Jek in Kecamatan Cibinong. The results of the coefficient of determination show that the value Adjust $R$ Square of 0,446 (44,6\%) Which means together factors cost, the quality of services and E-Commerce have contribution or affecting decision to use Go-Jek in Kecamatan Cibinong of 44,6\%, while the rest 55,4\% affect by the other factors that is not discussed in the research. The results of the hypothesis whether partial and simultaneously Prove that factors price, the quality of services and e-commerce affect decision costumers using Go-Jek in Kecamatan Cibinong. The most dominant factors affecting decision to using go-jek in Kecamatan Cibinong is a factor information technology E-Commerce, this is proven by value the regression coefficient of 0,678.
\end{abstract}

Keywords: Price, Quality of Services, Technology E-Commerce, The Decision Customers.

\begin{abstract}
ABSTRAK
Masyarakat saat ini banyak memanfaatkan E-Commerce untuk transportasi online, Go-Jek merupakan salah satu transportasi online alternatif yang dugunakan masyarakat saat ini.Tujuan penelitian ini untukmengetahui pengaruh faktor harga, kualitas layanan, dan teknologi $E$ Commerce terhadap keputusan untuk menggunakan layanan Go-Jek di wilayah Kecamatan Cibinong. Jenis penelitian ini adalah penelitian korelasional. Analisa data menggunakanregresi linear berganda denganbantuan program SPSS versi17.0. Hasil penelitianmenunjukkan hasil uji regresi linear berganda diperoleh persamaan regresi yaitu: $\mathrm{Y}=3.340+0,631 \mathrm{X} 1+0,180 \mathrm{X} 2+$ $0,678 \mathrm{X} 3$, yang artinya adalah bahwa setiap ada peningkatan nilai variabel bebas (harga, kualitas layanan dan E-Commerce) maka akan meningkatkan nilai keputusan konsumen menggunakan go-jek di wilayah kecamatan Cibinong. Hasil Uji koefisien determinasi menunjukkan bahwa nilai Adjusted $R$ Square sebesar 0,446 (44,6\%) yang berarti secara bersama-sama faktor harga, kualitas layanan dan E-Commerce mempunyai kontribusi atau mempengaruhi keputusan konsumen menggunakan go-jek di wilayah Kecamatan Cibinong sebesar 44,6\%, sedangkan sisanya 55,4\% di pengaruhi oleh faktor-faktor lain yang dalam penelitian ini tidak dibahas. Hasil uji hipotesis baik secara parsial maupun secara simultan membuktikan bahwa faktor harga, kualitas layanan dan E-Commerce mempengaruhi keputusan konsumen menggunakan go-jek di wilayah Kecamata Cibinong. Faktor yang paling dominan mempengaruhi keputusan konsumen menggunakan go-jek di wilayah Kecamatan Cibinong adalah faktor teknologi informasi E-Commerce, hal ini dibuktikan dengan nilai koefisien regresi sebesar 0,678.
\end{abstract}

Kata kunci: Harga, Kualitas Layanan, Teknologi E-Commerce, Keputusan Konsumen. 
1. PENDAHULUAN

\subsection{Latar Belakang Masalah}

Saat ini teknologi informasi mengalami perkembangan yang sangat pesat dimana perkembangannya tidak bisa kita hindari. Perkembangan teknologi informasi dapat membantu cara hidup kita menjadi lebih modern, lebih mudah dan lebih praktis dalam kehidupan sehari-hari.

Dengan adanya mekanisme bisnis secara elektronis, fenomena yang terjadi saat ini adalah masyarakat lebih memilih produk dan jasa yang lebih praktis, lebih efisien waktu, lebih mudah, harga terjangkau dan kualitas layanan yang memuaskan. Oleh karena itu, masyarakat saai ini banyak yang lebih memilih produk atau jasa yang memanfaatkan E-commerce untu berbelanja online, memesan tiket online, atau memesan jasa transportasi online.

Gojek indonesia adalah perusahaan transportasi asal Indonesia yang melayani angkutan melalui jasa ojek. Perusahaan ini didirikan pada tahun 2011 di Jakarta oleh Nadim Makarim. Awalnya Go-Jek melayani lewat panggilan telepon saja, tetapi semakin lama gojek semakin berkembang pada awal tahun 2015 Go-Jek meluncurkan aplikasi android Go-Jek. Kini fitur dan layanan yang ditawarkan Go-Jek makin beragam. Dalam perusahaan online, keputusan konsumen dalam melakukan suatu pembelian dipengaruhi oleh beberapa faktor.

Sejak meluncurkan aplikasi online pada awal 2015 dengan tarif yang bersaing dan terus melakukan inovasi-inovasi terhadap jenis layanan yang diberikan, serta fitur aplikasi yang makin mudah digunakan didukung dengan bertambah banyaknya pengguna smartphone di Indonesia, jumlah order GO-Jek terus bertambah. Go-Jek telah resmi beroperasi di 10 kota besar Jakarta, Bandung, Bali, Surabaya, Makassar, Yogyakarta, Medan, Semarang,
Palembang dan Balikpapan dengan pencana pengembangan dikota-kota lainnya.

Berdasarkan uraian diatas ,aka dari itu penulis mengambil judul "Pengaruh Harga, Kualitas Layanan dan Teknologi E-commerce terhadap Keputusan Untuk mMenggunakan Layanan Go-Jek di Wilayah Kecamatan Cibinong-Bogor".

\subsection{Perumusan Masalah}

Dalam penelitian ini perumusan masalahnya adalah apakah faktor harga, kualitas layanan dan teknologi e-commerce berpengaruh signifikan terhadap keputusan untuk menggunakan layanan Go-Jek dan faktor-faktor harga, kualitas layanan dan teknologio e-commerce, faktor manakah yang memiliki pengaruh paling besar terhadap keputusan untuk menggunakan layanan Go-Jek.

\subsection{Tujuan Penelitian}

Adapun tujuan dari penelitian yang akan dilaksanakan yaitu mengetahui bagaimana pengaruh faktor harga, kualitas layanan, dan teknologi e-commerce terhadap keputusan untuk menggunakan layanan Go-Jek dan mengetahui manakah dari faktor-faktor tersebut yang mempunyai pengaruh dominan terhadap keputusan untuk menggunakan layanan Go-Jek.

\section{TINJAUAN PUSTAKA}

\subsection{Landasan Teori}

\subsubsection{PEMASARAN}

Pemasaran adalah proses penyusunan komunikasi terpadu yang bertujuan untuk memberikan informasi mengenai barang atau jasa dalam kaitannya dengan memuaskan kebutuhan dan keinginan manusia.

Menurut Kotler \& Keller (2009:5): "Pemasaran adalah sebuah proses kemasyarakatan dimana individu kelompok yang memperoleh apa yangmereka butuhkan dan inginkan dengan menciptakan, menawarkan dan secara bebas 
mempertukarkan produk dan jasa yang bernilai dengan pihak lain".

\subsubsection{JASA}

Jasa merupakan sesuatu yang tidak dapat dilihat, tidak berwujud, cepat hilang namun dapat dirasakan dampaknya daripada dimiliki. Konsumen dapat berpartisipasi aktif dalam mengkonsumsi jasa tersebut. Didalam strategi pemasaran, definisi jasa harus dicermati dengan baik karena pengertiannya berbeda dengan produk. Menurut Kotler (2003), mendefinisikan jasa adalah aktivitas atau manfaat yang ditawarkan oleh satu pihak lain yang pada dasarnya tanpa wujud dan tidak menghasilkan kepemilikan apapun.

\subsubsection{KEPUTUSAN PEMBELIAN}

Menurut Kotler dan Armstrong (2001: 226) keputusan pembelian adalah tahap dalam proses pengambilan keputusan pembeli dimana konsumen benar benar akan membeli. Berdasarkan tujuan pembelian, konsumen dapat diklasifikasikan menjadi dua kelompok, yaitu konsumen akhir (individual) dan konsumen organisasional (konsumen industrial, konsumen antara, konsumen bisnis). Konsumen akhir terdiri atas individu atau rumah tangga yang tujuan akhirnya adalah untuk memenuhi kebutuhan sendiri atau untuk konsumsi, sedangkan konsumen organisasional terdiri atas organisasi, pemakai industri, pedagang, dan lembaga non profit yang tujuan pembeliannya adalah untuk keperluan bisnis (memperoleh laba) atau meningkatkan kesejahteraan anggotanya.

\subsubsection{HARGA}

Dalam konteks pemasaran, secara sederhana istilah harga dapat diartikan sebagai jumlah uang (satuan moneter) dan/atau aspek lain (nonmoneter) yang mengandung utilitas atau kegunaan tertentu yang diperlukan untuk mendapatkan suatu jasa (Tjiptono 2007, h.178 dalam Alam 2012 h.22 ). Harga yang sudah dibayar oleh pembeli sudah termasuk pelayanan yang diberikan oleh penjual. Dan tidak dipungkiri penjual juga menginginkan sejumlah keuntungan dari harga tersebut.

H1 : Variabel Persepsi harga berpengaruh positif terhadap keputusanMenggunakan Layanan GoJek.

\subsubsection{KUALITAS LAYANAN}

Menurut Wyckofdalam(Tjiptono, 2007:206), kualitas pelayanan merupakan tingkat keunggulan (excellence) yang diharapkan dan pengendalian atas keunggulan tersebut untuk memenuhi keinginan pelanggan. Kualitas jasa dipengaruhi dua hal, yaitu jasa yang dirasakan (perceived service) dan jasa yang diharapkan (expected service), bila jasa yang dirasakan lebih kecil dari pada yang diharapkan para pelanggan menjadi tidak tertarik pada penyedia jasa akan tetapi apabila yang terjadi adalah sebaliknya (perceived expected), ada kemungkinan para pelanggan akan mengunakan penyedia jasa itu lagi ( Rangkuti, dalamNugroho, 2008). Tingkat kualitas pelayanan jasa tidak dapat diukur berdasarkan sudut pandang perusahaan tetapi dipandang dari sudut pandang penilaian pelanggan (RangkutridalamNugroho, 2008).

H2 : Variabel kualitas layanan berpengaruh positif terhadap keputusan Menggunakan Layanan Go-Jek.

\subsubsection{TEKNOLOGI INFORMASI ( $E$ - commerce)}

Teknologi Informasi (TI) dilihat dari kata penyusunnya adalah teknologi dan informasi. Kata teknologi bermakna pengembangan dan penerapan berbagai peralatan atau sistem untuk menyelesaikan persoalan-persoalan yang dihadapi oleh 
manusia dalam kehidupan sehari-hari, kata teknologi berdekatan artinya dengan istilah tata cara.

Menurut Azmi, Yan (2009: 2), "informasi adalah data yang diproses kedalam bentuk yang lebih berarti bagi penerima dan berguna dalam pengambilan keputusan, sekarang atau untuk masa yang akan datang”. Untuk lebih jelasnya berikut ini penulis kemukakan beberapa defenisi mengenai teknologi informasi.

H3 : Variabel Teknologi Inforasi (Ecommerce) berpengaruh positif terhadap keputusan Menggunakan Layanan GoJek.

\subsection{Kerangka Pemikiran}

Untuk memudahkan pemahaman mengenai keseluruhan rangkaian dari penelitian ini, maka disusunlah kerangka pemikiran sebagai berikut :

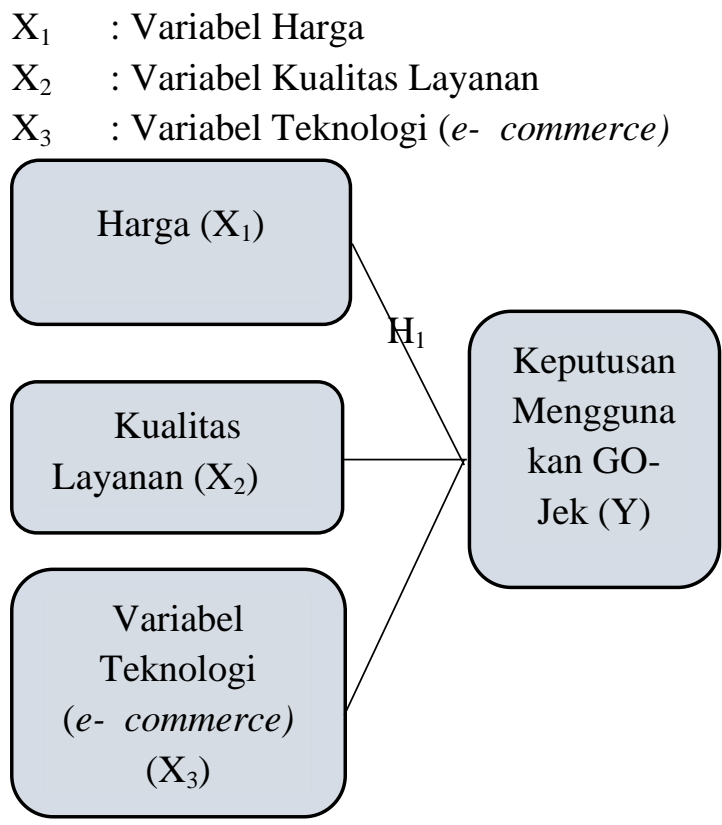

\section{Gambar 1. Kerangka Pemikiran Penelitian}

\subsection{Hipotesis}

Hipotesis merupakan suatu proporsi atau anggapan yang mungkin benar dan sering digunakan sebagai dasar pembuatan keputusan atau pemecahan masalah ataupun untuk dasar penelitian lebih lanjut (Suprapto,1993).

Hipotesis penelitian adalah dugaan sementara mengenai dua variabel atau lebih mengenai hasil penelitian. Hipotesis berperan sebagai pedoman pelaksanaan penelitian dan membantu peneliti membuat rancangan kesimpulan.

Adapun hipotesis yang diajukan dan diuji kebenarannya dalam penelitian ini adalah:

$\mathrm{H}_{1}$ : Variabel Harga berpengaruh positif terhadap keputusan Menggunakan Layanan Go-Jek.

$\mathrm{H}_{0}$ : Variabel Harga tidak berpengaruh positif terhadap keputusan Menggunakan Layanan Go-Jek.

$\mathrm{H}_{2}$ : Variabel Kualitas Layanan berpengaruh positif terhadap keputusan Menggunakan Layanan Go-Jek.

$\mathrm{H}_{0}$ : Variabel Kualitas Layanan tidak berpengaruh positif terhadapkeputusan Menggunakan Layanan Go-Jek.

$\mathrm{H}_{3}$ : Variabel Teknologi Inforasi (Ecommerce) berpengaruh positif terhadap keputusan Menggunakan Layanan Go-Jek. $\mathrm{H}_{0}$ : Variabel Teknologi Inforasi (Ecommerce) tidak berpengaruh positif terhadap keputusan Menggunakan Layanan Go-Jek.

\subsection{Objek Penelitian}

Objek penelitian dalam penulisan skripsi ini adalah masyarakat di wilayah Kecamatan Cibinong baik pelajar, mahasiswa, pekerja, atau pun masyarakat umum dengan usia 17 tahun ke atas.

\section{METODE PENELITIAN}

\subsection{Teknik Analisi Data Uji Instrumen}

Data dalam penelitian ini menggunakan data primer yang berasal dari kuesioner, untuk itu sebelum melakukan pengujian hipotesis, diperlukan pengujian 
validitas dan reabilitas terhadap pertanyaanpertanyaan kuesioner.

\subsubsection{AnalisisRegresi Linier Berganda}

Analisis regresi berganda yaitu suatu metode analisis yang digunakan untuk mengetahui seberapa besar pengaruh variabel pada variabel yang lain. Terdapat satu variabel dependen dan lebih dari satu variabel independen (Santoso dan Tjiptono, 2004).

Formula untuk regresi berganda adalah sebagai berikut:

$Y=\beta_{1} X_{1}+\beta_{2} X_{2}+\beta_{3} X_{3}+\varepsilon$

\subsubsection{Uji Penyimpangan Asumsi Klasik}

Uji ini dilakukan untuk mengetahui bahwa data yang diolah adalah sah (tidak terdapat penyimpangan), maka data tersebut akan diisi melalui uji asumsi klasik, yaitu Uji Normalitas Kolmogrov-Smirnov, Uji Heterokedastisitas dan Uji Multikolinearitas.

\subsubsection{Pengujian Hipotesis}

\section{a. UjiKoefisienDeterminasi $\left(\mathbf{R}^{2}\right)$}

Koefisien Determinasi $\left(\mathrm{R}^{2}\right)$ pada intinya mengukur seberapa jauh kemampuan model dalam menerangkan variasi variabel dependen.

\section{b. Uji Statistik t}

Uji $\mathrm{t}$ digunakan untuk menguji signifikasi konstanta dari setiap variabel independen.

\section{c. Uji Statistik F}

Uji $F$ pada dasarnya menunjukan apakah semua variabel bebas yang dimasukan dalam model mempunyai pengaruh secara bersama-sama terhadap variabel terkait.

\section{HASIL DAN PEMBAHASAN}

4.1 Hasil Analisis Data

4.1.1 Hasil Uji Validitas
Tabel 1. Hasil Uji Validitas Kuesioner

\begin{tabular}{|c|c|c|c|c|}
\hline \multirow{4}{*}{ Harga (X1) } & Pertanyaan & r-hitung & r-tabel & Keterangan \\
\cline { 2 - 5 } & X1.1 & 0.727 & 0.1966 & Valid \\
\cline { 2 - 5 } & X1.2 & 0.756 & 0.1966 & Valid \\
\cline { 2 - 5 } & X1.3 & 0.816 & 0.1966 & Valid \\
\hline \multirow{4}{*}{$\begin{array}{c}\text { Kualitas } \\
\text { Layanan (X2) }\end{array}$} & X2.1 & 0.672 & 0.1966 & Valid \\
\cline { 2 - 5 } & X2.2 & 0.617 & 0.1966 & Valid \\
\cline { 2 - 5 } & X2.3 & 0.706 & 0.1966 & Valid \\
\cline { 2 - 5 } & X2.4 & 0.725 & 0.1966 & Valid \\
\cline { 2 - 5 } & X2.5 & 0.656 & 0.1966 & Valid \\
\hline E-Commerce & X3.1 & 0.871 & 0.1966 & Valid \\
\cline { 2 - 5 } (X3) & X3.2 & 0.862 & 0.1966 & Valid \\
\hline \multirow{3}{*}{$\begin{array}{c}\text { Keputusan } \\
\text { menggunakan }\end{array}$} & Y1 & 0.725 & 0.1966 & Valid \\
\cline { 2 - 5 } Go-Jek (Y) & Y2 & 0.799 & 0.1966 & Valid \\
\cline { 2 - 5 } & Y3 & 0.858 & 0.1966 & Valid \\
\hline
\end{tabular}

Sumber: Data Primer yang diolah, 2016

Berdasar tabel dapat dilihat bahwa nilai koefisien korelasi atau r-hitung untuk nilai masing-masing peryataan/instrumen pengukur varibel dalam penelitian ini nilainya menunjukan angka yang lebih besar dari nilai r-tabel $(0,1966)$ jadi masingmasing pernyataan dinyatakan valid.

\subsubsection{Hasil Uji Reliabilitas}

Tabel 2. Hasil Reliabilitas Kuesioner.

\begin{tabular}{|c|c|c|c|}
\hline Variabel & Cronbach Alpha (a, & Standar Reliabilitus & Keterrangan \\
\hline Harga XI) & 0.650 & 0.60 & Reliabel \\
\hline Kualitas Layanan (X2) & 0.101 & 0.60 & Reliablel \\
\hline E-Conmerce (X3) & 0.667 & 0.60 & Reliablel \\
\hline 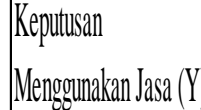 & 0.006 & 0.60 & Reliablel \\
\hline
\end{tabular}

Sumber: Data Primer yang diolah, 2016 
Berdasarkan hasil uji reliabilitas seperti pada tabel diatas diketahui bahwa nilai Cronbach's Alpha diperoleh dengan masing-masing nilai variabel $\mathrm{X} 1$ sebesar 0,650 , variabel $\mathrm{X} 2$ sebesar 0,701 , variabel $\mathrm{X} 3$ sebesar 0,667 dan variabel $\mathrm{Y}$ sebesar 0,806 yang berarti lebih dari 0,06. Dengan demikian dari hasil uji reliabilitas dapat diambil kesimpulan bahwa peryataan/instrumen yang digunakan dalam penelitian ini dinyatakan reliabel dan data yang diolah handal.

\subsection{Hasil Uji Asumsi Klasik}

4.2.1 Hasil Uji Normalitas KolmogorovSmirnov

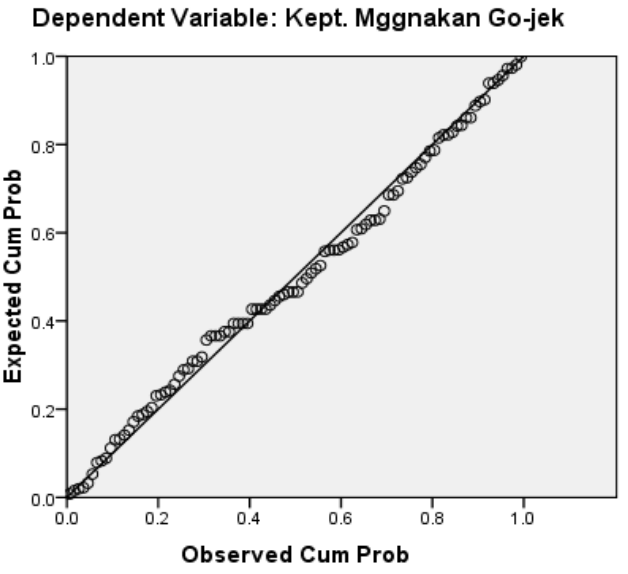

Gambar Hasil Uji Normalitas p-plot

Sumber: Data Primer yang diolah, 2016

Berdasarkan pada grafik normal pplot residual menunjukan bahwa titiktitik data menyebar disekitar garis diagonal yang mengarah kekanan atas serta penyebarannya mengikuti arah garis diagonal. Dengan demikian data tersebut bisa dikatakan mempunyai sebaran normal.

\section{Tabel 3. Hasil Uji $\quad$ Normalitas Kolmogorov-Smirnov}

\begin{tabular}{|c|c|c|}
\hline \multicolumn{3}{|c|}{ One-Sample Kolmogorov-Smirnov Test } \\
\hline & & $\begin{array}{c}\text { Unstandardized } \\
\text { Residual }\end{array}$ \\
\hline \multicolumn{2}{|l|}{$\mathrm{N}$} & 100 \\
\hline \multirow{2}{*}{$\begin{array}{l}\text { Normal } \\
\text { Parameter } \\
\mathrm{s}^{\mathrm{a}, \mathrm{b}}\end{array}$} & Mean & ,0000000 \\
\hline & $\begin{array}{l}\text { Std. } \\
\text { Deviation }\end{array}$ & 1,52495991 \\
\hline \multirow{3}{*}{$\begin{array}{l}\text { Most } \\
\text { Extreme } \\
\text { Difference } \\
\text { s }\end{array}$} & Absolute & ,055 \\
\hline & Positive & 043 \\
\hline & Negative &,- 055 \\
\hline \multicolumn{2}{|c|}{ Kolmogorov-Smirnov } &, 553 \\
\hline \multicolumn{2}{|c|}{ As ymp. Sig. (2-tailed) } & ,920 \\
\hline
\end{tabular}

Sumber: Data Primer yang diolah, 2016

Pada tabel uji kolmogorov-Smirnov menunjukan bahwa residual data yang didapat tersebut mengikuti distribusi normal, berdasarkan hasil output menunjukan nilai Kolmogorov-Smirnov signifikan pada 0,920>0,05. Dengan demikian, residual data berdistribusi normal dan model regresi telah memenuhi asumsi normalitas.

\subsubsection{Hasil Uji Heterokedastisitas \\ Scatterplot}

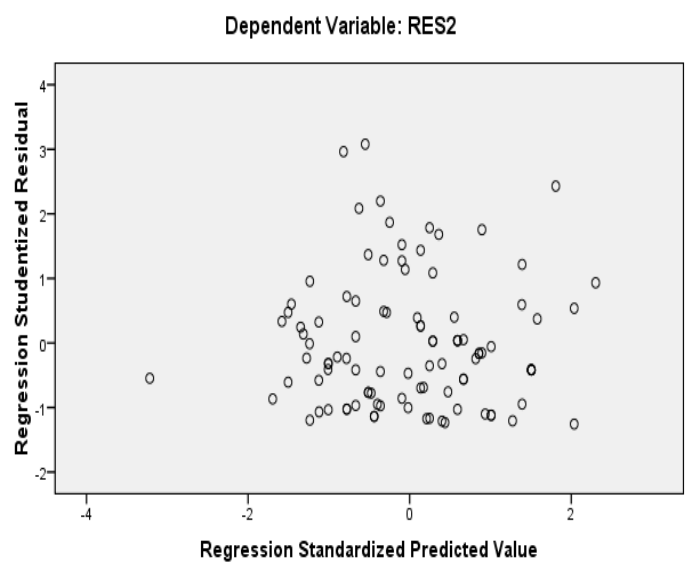

Gambar Hasil Uji Penyimpangan Heterokedastisitas

Sumber: Data Primer yang diolah, 2016 


\section{Berdasarkan grafik scatterplot} menunjukan bahwa terdapat pola yang jelas serta titik yang menyebar diatas dan dibawah angka 0 pada sumbu Y. Maka hal ini berarti bahwa varians (ragam) dari selutuh varabel bebas tidak berbeda secara nyata (signifikan).

$$
\text { Adapun hasil uji statistik }
$$

Heterokedastisitas dengan Uji Gletser yang diperoleh dalam penelitian ini adalah sebagai berikut :

Tabel 4. Hasil Uji Penyimpangan Heterokedastisitas

\begin{tabular}{|c|c|c|c|c|c|c|}
\hline \multicolumn{7}{|c|}{ Coefficients ${ }^{\mathrm{a}}$} \\
\hline & & \multicolumn{2}{|c|}{$\begin{array}{l}\text { Unstandardized } \\
\text { Coefficients }\end{array}$} & \multirow{2}{*}{\begin{tabular}{|c|}
$\begin{array}{c}\text { Standardized } \\
\text { Coefficients }\end{array}$ \\
Beta
\end{tabular}} & \multirow[b]{2}{*}{$t$} & \multirow[b]{2}{*}{ Sig. } \\
\hline \multicolumn{2}{|c|}{ Model } & $B$ & Std. Error & & & \\
\hline & (Constant) &, 715 & 1,260 & &, 568 & 5,572 \\
\hline & Harga & -018 & ,088 & -023 & -204 & 839 \\
\hline & $\begin{array}{l}\text { Kualitas } \\
\text { Layanan }\end{array}$ & 031 & 049 & ,074 &, 628 &, 531 \\
\hline & E-Commerce & 008 & 111 & ,008 & 070 &, 945 \\
\hline
\end{tabular}

Sumber: Data Primer yang diolah, 2016

Berdasarkan hasil uji heterokedastisitas diketahui bahwa nilai signifikasi variabel Harga (X1) adalah 0.839 lebih besar dari 0.05 artinya tidak terjadi heterokedatisitas. Untuk variabel kualitas layanan (X2) adalah 0.531 lebih besar dari 0.05 artinya tidak terjadi heterokedastisitas. Dan untuk variabel $E$ commerce (X3) nilai signifikasinya adalah 0.945 lebih besar dari 0.05 artinya tidak terjadi heterokedastisitas. Dapat disimpulkan bahwa ragam (varians) untuk variabel bebas adalah homogen/ sama (tidak terjadi heterokedastisitas). Model regresi yang baik adalah yang tidak terjadi heterokedastisitas.
4.2.3 Hasil Uji Multikolinearitas

Tabel 5. Hasil Uji Multikolinearitas

\begin{tabular}{|c|c|c|c|c|c|c|c|}
\hline \multicolumn{8}{|c|}{ Coefficients $^{a}$} \\
\hline \multirow[b]{2}{*}{ Model } & \multicolumn{2}{|c|}{$\begin{array}{l}\text { Unstandardized } \\
\text { Coefficients }\end{array}$} & $\begin{array}{c}\text { Standar } \\
\text { dized } \\
\text { Coefficie } \\
\text { nts }\end{array}$ & \multirow[b]{2}{*}{ t } & \multirow[b]{2}{*}{ Sig. } & \multicolumn{2}{|c|}{$\begin{array}{l}\text { Collinearity } \\
\text { Statistics }\end{array}$} \\
\hline & $B$ & Std. Error & Beta & & & Tolerance & VIF \\
\hline $\begin{array}{|ll|}1 & \text { (Cons } \\
& \operatorname{tant} t)\end{array}$ & 1,670 & 2,048 & &,- 815 &, 417 & & \\
\hline$X 1$ &, 631 & 143 & 364 & 4,413 &, 000 &, 821 & 1,218 \\
\hline X2 & 180, & ,080, & 194, & 2,255 & ,026, & ,752 & 1,330 \\
\hline$X_{3}$ &, 678 & 181 &, 321 & 3,748 &, 000 &, 763 & 1,311 \\
\hline
\end{tabular}

Sumber: Data Primer yang diolah, 2016

Dari hasil pengujian multikolinearitas yang dilakukan diketahui bahwa nilai variance inflation factor (VIF) ketiga variabel independen tidak terjadi multikolinearitas dengan ditunjukan oleh niali VIF dari ketiga variabel independen yang lebih kecil dari 10 dan nilai tolerance dari ketiga variabel lebih besar dari 0.10 .

\subsection{Hasil Analisis Regresi Linear Berganda}

Tabel 6. Hasil Uji Regresi Linier Berganda

\begin{tabular}{|c|c|c|c|c|c|c|}
\hline \multicolumn{7}{|c|}{ Coefficients $^{\mathrm{a}}$} \\
\hline \multirow{2}{*}{\multicolumn{2}{|c|}{ Model }} & \multicolumn{2}{|c|}{$\begin{array}{l}\text { Unstandardized } \\
\text { Coefficients }\end{array}$} & \multirow{2}{*}{ 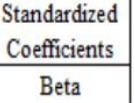 } & \multirow[t]{2}{*}{$t$} & \multirow[t]{2}{*}{ Sig. } \\
\hline & & B & Std. Error & & & \\
\hline \multirow[t]{4}{*}{1} & (Constant) & 3,34 & 4,096 & &, 815 & \\
\hline & Harga &, 631 &, 143 & 364 & 4,413 &, 000 \\
\hline & $\begin{array}{l}\text { Kualitas } \\
\text { Layanan }\end{array}$ &, 180 &, 080 & 194 & 2,255 &, 006 \\
\hline & E-Commerce &, 678 &, 181 &, 321 & 3,748 &, 000 \\
\hline
\end{tabular}

Sumber: Data Primer yang diolah, 2016

Perthitungan regresi linier berganda untuk memprediksi besarnya variabel terkait terhadap variabel bebas. Persamaan regresi yang digunakan yaitu sebagai berikut :

$\mathrm{Y}=3.340+0,631 \mathrm{X} 1+0,180 \mathrm{X} 2+0,678 \mathrm{X} 3$ 


\subsection{Hasil Uji Korelasi}

Tabel 7. Hasil Uji Koefisien Korelasi

\begin{tabular}{|c|c|c|c|c|c|c|}
\hline \multicolumn{7}{|c|}{ Correlations } \\
\hline & & $\begin{array}{l}\text { Keputusan } \\
\text { Menggunaan } \\
\text { Go Jek }\end{array}$ & Harga & $\begin{array}{l}\text { Kualitas } \\
\text { Layanan }\end{array}$ & \multicolumn{2}{|c|}{ ecommerce } \\
\hline \multirow[t]{4}{*}{$\begin{array}{l}\text { Pearson } \\
\text { Correlatio }\end{array}$} & ion & $\begin{array}{l}\text { Keputusan } \\
\text { Menggunaan } \\
\text { Go Jek }\end{array}$ & 1,000 &, 548 & , 471 &, 535 \\
\hline & & Harga &, 548 & 1,000 & 368 & 351 \\
\hline & & $\begin{array}{l}\text { Kualitas } \\
\text { Layanan }\end{array}$ &, 471 &, 368 & 1,000 & 443 \\
\hline & & e Commerce &, 535 &, 351 & 443 & 1,000 \\
\hline \multirow[t]{4}{*}{$\begin{array}{l}\text { Sig. } \\
\text { (1- } \\
\text { tailed) }\end{array}$} & \multicolumn{2}{|c|}{$\begin{array}{l}\text { Keputusan } \\
\text { Menggunaan } \\
\text { Go Jek }\end{array}$} & &, 000 &, 000 &, 000 \\
\hline & \multicolumn{2}{|c|}{ Harga } &, 000 & &, 000 &, 000 \\
\hline & \multicolumn{2}{|c|}{ KualitasLayanan } &, 000 & 000 & &, 000 \\
\hline & \multicolumn{2}{|c|}{ ecommerce } & 000 &, 000 &, 000 & \\
\hline \multirow[t]{4}{*}{$\mathrm{N}$} & \multicolumn{2}{|c|}{$\begin{array}{l}\text { Menggunaan } \\
\text { Go Jek }\end{array}$} & 100 & 100 & 100 & 100 \\
\hline & \multicolumn{2}{|c|}{ Harga } & 100 & 100 & 100 & 100 \\
\hline & \multicolumn{2}{|c|}{ KualitasLayanan } & 100 & 100 & 100 & 100 \\
\hline & \multicolumn{2}{|c|}{ ecommerce } & 100 & 100 & 100 & 100 \\
\hline
\end{tabular}

Sumber: Data Primer yang diolah, 2016

Dasar pengambilan keputusan dalam uji korelasi Spearman :

1. Berdasar Nilai Signifikasi

Jika nilai sig $<0,05$ maka dapat disimpulkan bahwa terdapat korelasi yang signifikan antara variabel yang dihubungkan. Berdasarkan tabel tersebut semua nilai signya $0,000<$ 0,05 maka dapat disimpulkan bahwa terdapat korelasi yang signifikan antara : Harga dan keputusan menggunakan G0-Jek, kualitas layanan dan keputusan menggunakan Go-Jek, dan antara teknologi informasi (Ecommerce) dan keputusan menggunakan Go-Jek.

2. Kriteria tingkat hubungan (koefisien korelasi) antar variabel berdasarkan hasil uji Koefisien Korelasi Spearman dengan SPSS pada tabel tersebut adalah sebagai berikut :

a. Hubungan antara harga dengan keputusan menggunakan go-jek berada pada kriteria korelasi yang sedang sebesar 0,548.

b. Hubungan kualitas layanan dengan keputusan menggunakan go-jek berada pada kriteria korelasi sebebsar 0,471 .

c. Hubungan e-commerce dengan keputusan menggunakan go-jek berada pada kriteria korelasi yang sedang sebesar 0,471 .

\subsection{Hasil Uji Koefisien Determinasi $\left(\mathbf{R}^{2}\right)$}

Tabel 8. Hasil Uji Koefisien Detrminasi $\left(\mathbf{R}^{2}\right)$

\begin{tabular}{|c|c|c|c|c|}
\hline \multicolumn{5}{|c|}{ Model Summary } \\
\hline Model & $\mathrm{R}$ & $\begin{array}{c}\text { R } \\
\text { Squar } \\
\text { e }\end{array}$ & $\begin{array}{c}\text { Adjuste } \\
\text { d R } \\
\text { Square }\end{array}$ & $\begin{array}{c}\text { Std. } \\
\text { Error } \\
\text { of the } \\
\text { Estima } \\
\text { te }\end{array}$ \\
\hline 1 &, $680^{a}$ & ,463 & ,446 & $\begin{array}{r}3,0972 \\
1\end{array}$ \\
\hline
\end{tabular}

a. Predictors: (Constant), eCommerce,

Harga, KualitasLayanan

b. Dependent Variable: Keputusan

Sumber: Data Primer yang diolah, 2016

Berdasarkan hasil uji koefisien determinasi menunjukan bahwa nilsi Adjusted $R$ Square sebesar 0,446 (44,6\%) yang berarti secara bersama-sama faktor harga, kualitas layanan dan e-commerce mempunyai kontribusi atau mempengaruhi keputusan konsumen menggunakan go-jek diwilayah Kecamatan Cibinong sebebsar $44,6 \%$ sedangkan sisanya $55,6 \%$ dipengaruhi oleh faktor-faktor lain yang dalam penelitian ini tidak dibahas.

\subsection{Hasil Uji Hipotesis}

\subsubsection{Hasil Uji Hipotesis Secara Parsial} (Uji t) 


\begin{tabular}{|c|c|c|c|c|c|}
\hline \multicolumn{6}{|l|}{$\begin{array}{l}\text { Tabel 9. Has } \\
\text { Parsial (Uji t) }\end{array}$} \\
\hline \multicolumn{6}{|c|}{ Coefficients $\mathrm{s}^{\mathrm{a}}$} \\
\hline \multirow[b]{2}{*}{ Model } & \multicolumn{2}{|c|}{\begin{tabular}{|c|} 
Unstandardized \\
Coefficients \\
\end{tabular}} & \multirow{2}{*}{\begin{tabular}{|c|}
$\begin{array}{c}\text { Standardized } \\
\text { Coefficients }\end{array}$ \\
Beta \\
\end{tabular}} & \multirow[b]{2}{*}{$t$} & \multirow[b]{2}{*}{ Sig. } \\
\hline & B & $\begin{array}{c}\text { Stdd. } \\
\text { Error }\end{array}$ & & & \\
\hline \begin{tabular}{l|l}
1 & (Constant)
\end{tabular} & 3,340 & 4,096 & & 815 &, 417 \\
\hline Harga &, 631 & 143 &, 364 & 4,413 &, 000 \\
\hline KualitasLayanan & , 180 & 080 & 194 & 2,255 &, 006 \\
\hline ecommerce & 678 & 181 &, 321 & 3,748 &, 000 \\
\hline
\end{tabular}

Sumber: Data Primer yang diolah, 2016

Untuk menguji keberartian model regresi untuk masing-masing variabel secara parsial dapat di peroleh dengan menggunakan uji t. Hipotesis diterima jika nilai t hitung $>\mathrm{t}$ tabel untuk sampel yang berjumlah 100 nilai $\mathrm{t}$ tabeladalahsebesar 1.696.

\subsubsection{Uji Hipotesis Secara Simultan (Uji F )}

Tabel 10. Hasil Uji Hipotesis Secara Simultan (Uji F)

\begin{tabular}{|c|c|c|c|c|c|}
\hline \multicolumn{6}{|c|}{ ANOVA } \\
\hline Model & $\begin{array}{l}\text { Sum of } \\
\text { Squares }\end{array}$ & $d f$ & Mean Square & $F$ & Sig. \\
\hline \begin{tabular}{|l|l|}
1 & Regression \\
\end{tabular} & 794,101 & 3 & 264,700 & 27,594 & $000^{\circ}$ \\
\hline Residual & 920,899 & 96 & 9,593 & & \\
\hline Total & 1715,000 & 99 & & & \\
\hline
\end{tabular}

Sumber: Data Primer yang diolah, 2016

Dari tabel ANOVA seperti tampak pada tabel 4.15 di atas di peroleh nilai $\mathrm{F}$ sebesar 27.594 dengan $P$ Sig. 0,000. Dengan pengujian hipotesis maka dapat di simpulkan bahwa nilai P Value $(0,000)<$ $5 \%$, hal ini membuktikan bahwa persamaan regresi yang diperoleh dari hasil pengujian ini layak digunakan.Dengan ketentuan hipotesis bahwa, jika $\mathrm{F}$ hitung > F tabel maka Ho ditolak dan Ha diterima maka, dengan demikian hipotesis yang menyatakan bahwa harga, kualitas layanan dan e-Comerce secara bersama-sama memiliki pengaruh positif dan siginifikan terhadap keputusan konsumen menggunakan go-jek di wilayah Kecamatan Cibinong (Ha) dapat diterima. Sedangkan hipotesis yang menyatakan bahwa bahwa harga, kualitas layanan dan e-Comerce secara bersama-sama tidak memiliki pengaruh positif dan siginifikan terhadap keputusan konsumen menggunakan go-jek di wilayah Kecamatan Cibinong (Ho) di tolak.

\section{KESIMPULAN DAN SARAN}

\subsection{Kesimpulan}

Berdasarkan hasil penelitian yang telah dijelaskan pada bab sebelumnya maka kesimpulan yang dapat diambil dari penelitian ini adalah:

1. Hasil uji korelasi membuktikan bahawa terdapat hubungan yang sedang antara variabel bebas (harga, kualitas layanan, dan e-commerce dengan keputusan konsumen menggunakan go-jek di wilayah Kecamatan Cibinong.

2. Hasil uji regresi linear berganda diperoleh persamaan regresi yaitu: $\mathrm{Y}=$ $3.340+0,631 \mathrm{X} 1+0,180 \mathrm{X} 2+0,678 \mathrm{X} 3$. yang artinya adalah bahwa setiap ada peningkatan nilai variabel bebas (harga, kualitas layanan dan $e$ commerce) maka akan meningkatkan nilai keputusan konsumen menggunakan go-jek di wilayah kecamatan Cibinong. Sedangkan jika tidak ada peningkatan nilai variabel bebas maka nilai keputusan konsumen menggunakan go-jek akan konstan sebesar 3.340.

3. Hasil Uji koefisien determinasi menunjukkan bahwa nilai Adjusted $R$ Square sebesar $0,446(44,6 \%)$ yang berarti secara bersama-sama faktor harga, kualitas layanan dan $e$ - 
commerce mempunyai kontribusi atau mempengaruhi keputusan konsumen menggunakan go-jek di wilayah Kecamatan Cibinong sebesar 44,6\%, sedangkan sisanya $55,4 \%$ di pengaruhi oleh faktor-faktor lain yang dalam penelitian ini tidak dibahas.

4. Hasil uji hipotesis baik secara parsial maupun secara simultan membuktikan bahwa faktor harga, kualitas layanan dan e-commerce mempunyai kontribusi atau mempengaruhi keputusan konsumen menggunakan go-jek di wilayah Kecamata Cibinong.

5. Berdasarkan hasil uji regresi diketahui bahwa faktor yang paling dominan mempengaruhi keputusan konsumen menggunakan go-jek di wilayah Kecamatan Cibinong adalah faktor teknologi informasi e-commerce, hal ini dibuktikan dengan nilai koefisien regresi sebesar 0,678.

\subsection{Saran}

Dari pemaparan kesimpulan penelitian di atas maka saran-saran yang dapat penulis sampaikan adalah:

1. Berdasarkan hasil penelitian, kualitas layanan memiliki nilai koefisien regresi paling kecil dibanding faktor harga dan teknologi informasi (ecommerce). Oleh Karena itu perusahaan Go-jek hendaknya lebih meningkatkan kualitas pelayanannya agar pelanggan yang menggunakan layanan go-jek makin bertambah.

2. Perusahaan Go-Jek sebaiknya lebih sering memberikan potongan harga atau tarif promo untuk event-event tertentu untuk meningkatkan jumlah order karena berdasar penelitian potongan harga dan tarif promo dapat meningkatkan nilai keputusan konsumen untuk menggunakan Go-jek.

3. Faktor harga, kualitas layanan, dan teknologi informasi (e-commerce) mempengaruhi keputusan konsumen menggunakan go-jek di wilayah Kecamatan Cibinong sebesar44,6\% sedangkan $55,4 \%$ dipengaruhi faktor lain. Oleh karena itu perlu dilakukan penelitian yang mengkaji tentang faktor yang mempengaruhi keputusan menggunakan go-jek selain tiga faktor di atas.

\section{DAFTAR PUSTAKA}

Akbar M.M and Parvez. 2009. Impact of Service Quality, Trust, and Customer Satisfaction Loyalty, ABAC Journal.

Bayu Argi Nugroho.2008. Pengaruh Harga, Promosi dan Kualitas Pelayanan Terhadap Keputusan Pembelian Akses Internet Pada PT Data Utama Dinamika Semarang, Under Graduates thesis, Universitas Negeri Semarang.

Ferdinand, Augusty.2006. Metode Penelitian Manajemen : Pedoman Penelitian untuk Penulisan Skripsi, Tesis, dan Diserti Ilmu Manajemen, Badan Penerbit Universitas Diponegoro, Semarang.

Ghozali, Imam.2005. Aplikasi Analisis Multivariate dengan Program SPSS, Badan Penerbit Universitas Diponegoro, Semarang.

Jonathan Sarwono.2006. Metode Penelitian Kuantiyatif \& Kualitatif. Graha Ilmu, Yogyakarta

Kotler, Philip., Keller, Kevin Lane. 2009. Manajemen Pemasaran (Edisi 13 Jilid 1). Erlangga, Jakarta.

Kotler, Philip., Armstrong, Gary. 2003. Dasar-Dasar Pemasaran. Alih Bahasa. PT Indeks. Edisi 9, Jakarta.

Kotler, Philip., Armstrong, Gary. 2001. Prinsip-Prinsip Pemasaran, jilid 1Edisi ke delapan. Erlangga, Jakarta.

Kuncoro, Mudrajad. 2011. Metode Kuantitatif: Teori dan Aplikasi untuk Bisnis dan Ekonomi. Penerbit :UPP STIM YKPN.Yogyakarta. 
Lupiyoadi, Hamdani. 2008. Manajemen Pemasaran Jasa, Edisi Kedua. Penerbit Salemba Empat, Jakarta.

Sugiyono.Prof., Dr., 2004. Metode Penelitian Bisnis. Alfabeta, CV, Bandung.

Rao, Purba 1996, "Measuring Consumer Perception Through Factor Analysis", The Asian Manager, February-March, hal 28-32.

Schiffman dan Kanuk. 2007. Perilaku Konsumen. Edisi kedua. PT Indeks Gramedia, Jakarta.

Sutarman. 2009. Pengantar Teknologi Informasi. Bumi Aksara, Yogyakarta.

Suyanto M.2005. Pengantar Teknologi Informasi Untuk Bisnis. Penerbit Andi, Yogyakarta.

Tjiptono, Fandy. 2005. Pemasaran Jasa, Edisi Pertama. Penerbit Bayumedia Publishing Majid, Malang.

Tjiptono, Fandy. 2000. Manajemen Jasa. Penerbit: Andi, Yogyakarta.

http:///yanazmi.blogspot.com/2009/04/peng ertian-informasi.html, 29 September 2015 pukul 22 WIB.

https://www.merdeka.com/uang/menakarkeberhasilan-go-jek-merevolusisistem-ojek-pangkalan.html, September 2015 pukul 22 WIB.

https://id.wikipedia.org/wiki/Perdagangan_ elektronik, 11 Oktober 2015 pukul 23.00 WIB.

https://www.go-jek.com/howtojoin.htm 14 September 2015 pukul 21.00 WIB https://citizen6.liputan6.com/read/2320466/ 6-ojek-online-yang-menjadi-pesaing Go-Jek, 3 Februari 2016 pukul 20.00 WIB.

https://www.tothenew.com/blog/how-go jek-is-disrupting-the-marketinglandscape-in-indonesia/ 2 Februari 2016 pukul 22.00 WIB.

http://kecamatancibinong.bogorkab.go.id/ 3 Maret 2016 pukul 21.00.

http://www.infonitas.com/info_galeri/melo ngok-aktivitas-di-kantor- gojek/367\#ad-image-5 6 Maret 2016 Pukul 00.30 WIB.

http://www.apjii.or.id 15 Februari 2016 Pukul 20.00 WIB.

http://www.tothenew.com/15 Februari 2016 Pukul 22 WIB. 